\title{
How biological clocks and changing environmental conditions determine local population growth and species distribution in Antarctic krill (Euphausia superba): a conceptual model
}

\author{
Jürgen Groeneveld $^{\mathrm{a}, *}$, Karin Johst ${ }^{\mathrm{a}}$, So Kawaguchi ${ }^{\mathrm{b}, \mathrm{c}}$, Bettina Meyer ${ }^{\mathrm{d}, \mathrm{e}}$, Mathias Teschke ${ }^{\mathrm{d}}$, \\ Volker Grimma,f,g \\ a Helmholtz Centre for Environmental Research-UFZ, Department of Ecological Modelling, Permoserstr. 15, 04318 Leipzig, Germany \\ ${ }^{\mathrm{b}}$ Australian Antarctic Division, Kingston, TAS 7050, Australia \\ ${ }^{c}$ Antarctic Climate and Ecosystem Cooperative Research Centre, Hobart, TAS 7001, Australia \\ ${ }^{\mathrm{d}}$ Alfred Wegener Institute for Polar and Marine Research, Polar Biological Oceanography, D-27570 Bremerhaven, Germany \\ e Institute for Chemistry and Biology of the Marine Environment, Carl von Ossietzky University Oldenburg, Carl-von-Ossietzky-Straße 9-11, \\ 26111 Oldenburg, Germany \\ ${ }^{\mathrm{f}}$ University of Potsdam, Institute for Biochemistry and Biology, Maulbeerallee 2, 14469 Potsdam, Germany \\ ${ }^{g}$ German Centre for Integrative Biodiversity Research (iDiv) Halle-Jena-Leipzig, Deutscher Platz 5e, 04103 Leipzig, Germany
}

\section{A R T I C L E I N F O}

\section{Article history:}

Received 30 October 2014

Received in revised form 5 February 2015

Accepted 6 February 2015

\section{Keywords:}

Dynamic energy budget theory

Individual based model

Southern Ocean

Sea ice

Climate change

Marine ecology

\begin{abstract}
A B S T R A C T
The Southern Ocean ecosystem is characterized by extreme seasonal changes in environmental factors such as day length, sea ice extent and food availability. The key species Antarctic krill (Euphausia superba) has evolved metabolic and behavioural seasonal rhythms to cope with these seasonal changes. We investigate the switch between a physiological less active and active period for adult krill, a rhythm which seems to be controlled by internal biological clocks. These biological clocks can be synchronized by environmental triggers such as day length and food availability. They have evolved for particular environmental regimes to synchronize predictable seasonal environmental changes with important life cycle functions of the species. In a changing environment the time when krill is metabolically active and the time of peak food availability may not overlap if krill's seasonal activity is solely determined by photoperiod (day length). This is especially true for the Atlantic sector of the Southern Ocean where the spatio-temporal ice cover dynamics are changing substantially with rising average temperatures. We developed an individual-based model for krill to explore the impact of photoperiod and food availability on the growth and demographics of krill. We simulated dynamics of local krill populations (with no movement of krill assumed) along a south-north gradient for different triggers of metabolic activity and different levels of food availability below the ice. We also observed the fate of larval krill which cannot switch to low metabolism and therefore are likely to overwinter under ice. Krill could only occupy the southern end of the gradient, where algae bloom only lasts for a short time, when alternative food supply under the ice was high and metabolic activity was triggered by photoperiod. The northern distribution was limited by lack of overwintering habitat for krill larvae due to short duration of sea ice cover even for high food content under the ice. The variability of the krill's length-frequency distributions varied for different triggers of metabolic activity, but did not depend on the sea ice extent. Our findings suggest a southward shift of krill populations due to reduction in the spatial sea ice extent, which is consistent with field observations. Overall, our results highlight the importance of the explicit consideration of spatio-temporal sea ice dynamics especially for larval krill together with temporal synchronization through internal clocks, triggered by environmental factors (photoperiod and food) in adult krill for the population modelling of krill.
\end{abstract}

(C) 2015 Elsevier B.V. All rights reserved.

\footnotetext{
* Corresponding author. Tel.: +493412351711.

E-mail address: juergen.Groeneveld@ufz.de (J. Groeneveld).
} 


\section{Introduction}

Environmental conditions such as air temperature, water temperature, and sea ice dynamics are changing at an unprecedented rate in the Atlantic sector of the Southern Ocean ecosystem (Skvarca et al., 1999, Vaughan et al., 2003). Globally (Walther et al., 2002) and for both polar regions (Montes-Hugo et al., 2009, Schofield et al., 2010, Nielsen et al., 2013) species are already responding to climate change. The response of Antarctic krill (Euphausia superba from here on called krill) is of special interest due to its central role in the food web of the Southern Ocean (Loeb et al., 1997) and its growing importance for the fishery (Everson, 2000). Therefore the findings of recent studies regarding responses of krill to climate change, ocean acidification, and habitat change in krill are of public concern (Atkinson et al., 2004, Hill et al., 2013, Kawaguchi et al., 2013). At the same time krill is also known for its physiological plasticity and its ability to adapt to a wide range of environmental conditions as well as their seasonal fluctuation, allowing for krill's wide latitudinal distribution between $50^{\circ} \mathrm{S}$ (e.g. South Georgia) and $70^{\circ}$ S (e.g. Amundsen Sea) (Atkinson et al., 2004).

One of the overwintering strategies for adult krill is to reduce metabolic activity during winter when there is not much food available compared to summer period when massive algae blooms occur (Kawaguchi et al., 2007, Meyer 2012, Meyer et al., 2009, 2010). This reduced metabolic activity is hypothesized to be not only a response to reduced food availability but also driven by an endogenous timing system synchronized by the environmental 'Zeitgeber' photoperiod (Teschke et al., 2007, 2008, 2011, Meyer et al., 2010). It is crucial to understand the details of this endogenous timing mechanism to assess krill's capacity to adapt to climate change because the metabolic activity of krill and favourable environmental conditions could go out of phase in the future with unknown consequences. The impact of an internal timing mechanisms on krill's spatial distribution and population-level patterns such as demographic growth rate and size structure is so far unknown as well as which environmental factors (photoperiod or food, or both) act as 'Zeitgeber' to initiate the increasing metabolic activity in adult krill after the winter period. An additional important aspect of environmental conditions on the population dynamics of krill is the survival of krill larvae during winter. Krill larvae cannot reduce their metabolic activity and have to forage throughout the winter. Therefore sea ice has been suggested as overwintering habitat for krill larvae providing both shelter and food (Daly, 1990, Meyer et al., 2009). Being under the ice can be beneficial since retreating ice in spring, a stable surface layer due to low salinity, as well as sufficient light and nutrients promotes an algae bloom and hence favourable food conditions for both larvae and adults (Meyer et al., 2010). Furthermore, both larvae and adult krill may directly forage for algae growing underneath the sea ice (Daly, 1990).

There is a rich history of krill models investigating the growth of krill (see Candy and Kawaguchi, 2006 for an overview, Lowe et al., 2012 for a simulation model for krill larvae) and on the role of krill in food webs (e.g. Hill et al., 2012). There are fewer mechanistic models that allow simulating the physiological or behavioural response of krill to environmental changes. Stage-structured models considering energy budgets have been used to assess whether certain movement pathways from the Western Antarctic Peninsula to South Georgia are possible (Fach et al., 2002) and a "dynamic statevariable model", which is based on an optimization algorithm, has been used to explain shrinkage in individual krill size in response to predators (Alonzo and Mangel, 2001). Thus, to investigate the link between potential environmental triggers (i.e. day length and food availability), environmental change (sea ice coverage), internal biological clocks, and population structure and species distribution, we constructed a new individual-based model for krill, where we model 33 separate populations along a south-north gradient. We aimed to understand in which way environmental factors such as ice cover and metabolic shift affect local population growth and size structure. We specifically tested the impact of five environmental 'trigger' scenarios for krill, two different scenarios of the spatio-temporal ice cover dynamics, and different levels of food availability under the sea ice.

Our model includes a realistic description of krill growth, that is based on a recent version of Dynamic Energy Budget theory (DEBKiss; Jager et al., 2013), but the environmental settings and the assumption that krill does not move reflect that our purpose here was conceptual understanding, not a realistic representation of spatio-temporal dynamics of krill populations. Our 33 local krill populations represent 'probes' that translate assumptions about environmental triggers into assessments of local habitat quality for krill. We then take local habitat quality as a proxy for the potential distribution of krill.

\section{Methods}

\subsection{The model}

We developed an individual based model for krill that is available in the electronic supplementary material as appendix 1 . The model was implemented using the software platform NetLogo 5.0.2 (Wilensky, 1999). The model description below follows the ODD protocol (Overview, Design, and Details protocol, Grimm et al., 2006, 2010).

\subsubsection{Purpose}

We investigate the effect of climate change (in terms of changing ice cover dynamics), and the nature of the trigger of krill to switch metabolic activity (day length, food availability) on its individual growth in body length, frequency distribution of body length and age in the population, and species distribution.

\subsubsection{Entities, state variables and scales}

The model entities are krill individuals and spatial units. Krill individuals have the following state variables: body length [continuous, cm], age [integer, days], larval status [yes, no], maturity [continuous value], shrinkage [continuous, $\mathrm{cm}$ ], day length when metabolic activity changes depending on the scenario [continuous, hours], metabolic state [active, reduced], reproductive events [integer, dimensionless].

Krill are assumed stationary with no latitudinal directions movements, i.e. they stay their whole life at their position along the south-north gradient.

Spatial units, or grid cells (called patches in NetLogo), are arranged in a one-dimensional array along a south-north gradient (Fig. 1). Grid cells have the following state variables: food availability [continuous value $>0$ ], ice cover [covered or free], duration of algae bloom [integer, days], day length [continuous, hours].

Simulations run in daily time steps for 15 years. Before every simulation the model is run for one initialisation year without krill to initialize the environmental conditions such as food content. The spatial extent of the one-dimensional array of grid cells represents a latitudinal gradient, defined by the temporal ice cover dynamics and day length (maximum and minimum day length $16.8 \mathrm{~h}$ and $7.2 \mathrm{~h}$ for the top grid cell, respectively, and $24 \mathrm{~h}$ and $0 \mathrm{~h}$ for the bottom grid cell, corresponding to a latitudinal range between $50^{\circ} \mathrm{S}$ and $\left.70^{\circ} \mathrm{S}\right)$.

\subsubsection{Process overview and scheduling}

The following processes are performed each day in the given order (Fig. 2); entities are processed in a randomized sequence and state variables are updated immediately (all processes are 
No climate change (max ice cover $100 \%$ )

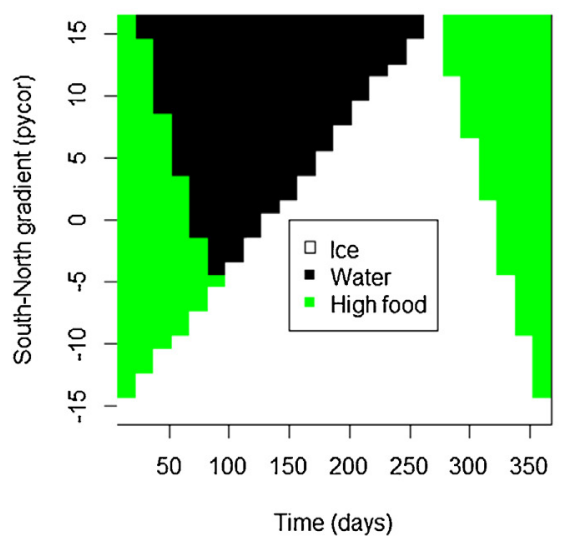

Climate change ( $\max$ ice cover $50 \%$ )

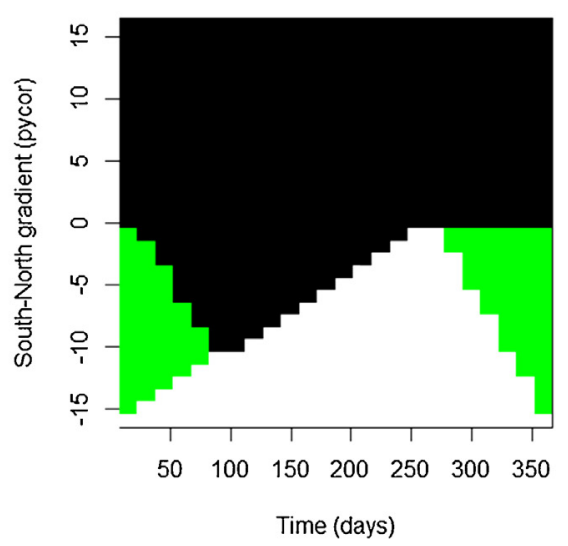

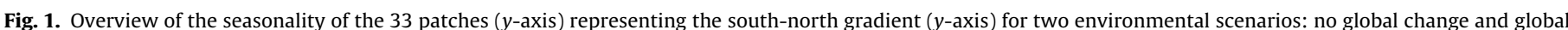

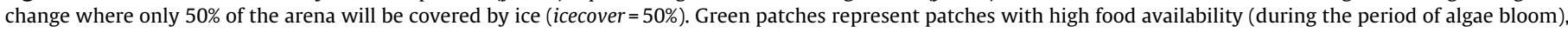

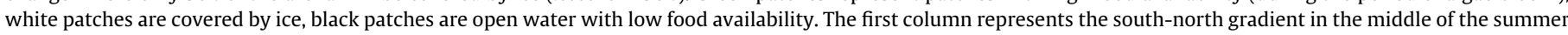

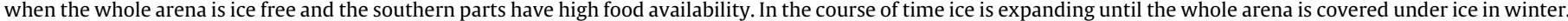

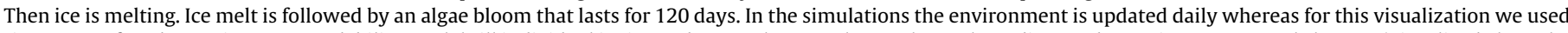

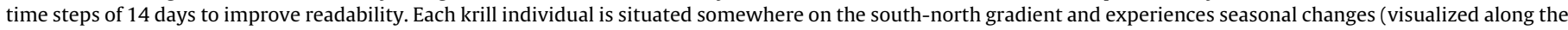
horizontal direction).

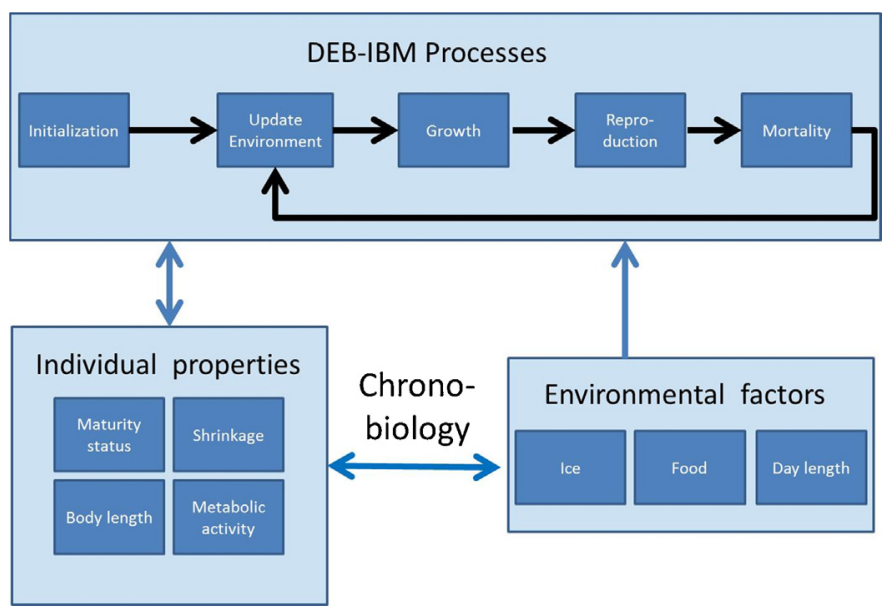

Fig. 2. Overview of the main processes in the deb-ibm krill model, state variables of krill, and the environmental factors considered in the model. Detailed explanations are given in the entities, state variables and scales Section 2.1.2, the initialization Section 2.1.5, and the sub-model Section 2.1.7.

explained in more detailed in Section 2.1.7): (i) Growth - individual growth or shrinkage in body length depend on food availability, larvae state, metabolic state, and current body length. (ii) Reproduction - adult krill can reproduce during metabolically active time (summer) depending on its maturity state. Multiple spawning events are possible during one year. (iii) Mortality - individual krill dies after 7 years deterministically. Furthermore krill die if they do not grow into adult status after two years or if their shrinkage cumulated up to their current age exceeds half of their current body length. (iv) Environment - based on the day of the year ice cover changes. In each grid cell, after ice melt there is an algae bloom that lasts for a certain time period (vegetation length $v_{\mathrm{g}}=120$ days). Day length along the latitudinal gradient is updated daily.

\subsubsection{Design concepts}

Basic principles: Reproduction and growth of individual krill are based on principles of a simplified version of the Dynamic Energy Budget theory (Kooijman, 2009, Jager et al., 2013).

Emergence: An emergent outcome of the individual life histories of krill is the growth dynamics of individuals, the local populations' size and age distribution, growth rate, and the geographic distribution of local populations.

Sensing: Krill does know the environmental state of the grid cell where it lives, i.e. food availability, ice cover, and day length.

Interaction: Krill do not interact.

Stochasticity: The model is deterministic. Please note that this does not mean that all individuals in a local population have identical growth trajectories. The reason is that the offspring of one cohort will usually be born on a different day than their parents, because reproduction happens when the maturity status exceeds a certain threshold. Therefore offspring face different environmental conditions than their parents which will result in cohort specific trajectories.

Observation: A local population is defined as all krill within one grid cell. Of these populations, we observe the size and age distribution of individuals, number of individuals, and the distribution of metabolically active days within a year. We also keep track of the reproductive events at the individual level.

\subsubsection{Initialization}

The model is populated with 330 krill larvae equally distributed among the 33 grid cells (10 individuals per grid cell) representing the south-north gradient. All individuals start in the same state: age (days) is set to zero, length is set to minimum length $\left(l_{0}=0.17 \mathrm{~cm}\right.$, length of Calyptopis I larvae (first feeding stage); Jia et al., 2014), maturity state is set to zero, shrinkage and life time reproductive events are set to zero. The simulation starts in the middle of summer where day length is at its maximum. To start with sensible environmental conditions we run the first year without krill to have the environmental conditions such as food concentrations and ice coverage according to the chosen environmental scenario.

\subsubsection{Input data}

We do not use external data.

\subsubsection{Submodels}

An overview of used parameters can be found in Table 1 .

Growth: Following dynamic energy budget theory, we model individual growth as follows (Kooijman, 2009, Jager et al., 2013): larvae growth is modelled during the whole year, whereas adults 
Table 1

Overview of state variables and parameters.

\begin{tabular}{|c|c|c|c|}
\hline Name & Explanation & Range & Reference value \\
\hline \multicolumn{4}{|c|}{ State variables of krill } \\
\hline$l$ & Body length $[\mathrm{cm}]$ & $0.17-7$ & Dynamic \\
\hline age & Age [days] & $0-2555$ (0-7 years) & Dynamic \\
\hline larvae & Life history stage [dimensionless] & true or false $=$ adult & Dynamic \\
\hline$m$ & Maturity state [dimensionless] & $0-m_{\text {th }}$ & Dynamic \\
\hline $\mathrm{sh}$ & Shrinkage $[\mathrm{cm}]$ & $0-\infty$ & Dynamic \\
\hline$s_{\mathrm{m}}$ & Metabolic state [dimensionless] & active or reduced & Dynamic \\
\hline ltre & Life time reproductive events [dimensionless] & $0-\infty$ & Dynamic \\
\hline \multicolumn{4}{|c|}{ State variables of patches } \\
\hline$X$ & Food density & 0-12 (sensu Tarling et al., 2006) & Dynamic \\
\hline ice & Patch covered by ice or not [dimensionless] & Covered-not covered & Dynamic \\
\hline age $_{\text {veg }}$ & Vegetation age [days] & $0-v_{\mathrm{g}}$ & Dynamic \\
\hline \multicolumn{4}{|c|}{ List of parameters } \\
\hline$A_{\text {world }}$ & Length of gradient [patches] & $1-\infty$ & 33 \\
\hline$N_{\text {init }}$ & Initial krill number [dimensionless] & $0-\infty$ & 330 \\
\hline$l_{0}$ & Initial krill body length $[\mathrm{cm}]$ & $0-l_{\mathrm{m}}$ & 0.17 \\
\hline icecover & Percentage of the gradient covered by ice [dimensionless] & $0-100$ & 100 \\
\hline$v_{\mathrm{g}}$ & Duration of algae bloom [days] & $0-364$ & 120 \\
\hline mdl & Metabolic switching day length [hours] & $0-24$ & 12 \\
\hline$K$ & Half saturation food density [dimensionless] & $0-\infty$ & 1 \\
\hline$r_{\mathrm{B}}$ & Daily Bertalanffy growth rate $\left[\right.$ day $\left.^{-1}\right]$ & $0-\infty$ & 0.003 \\
\hline$l_{\mathrm{m}}$ & Maximum body length $[\mathrm{cm}]$ & $0--\infty$ & 7 \\
\hline$l_{\text {adult }}$ & Body length when krill gets to adult stage [cm] & $0-\infty$ & 3 \\
\hline$m_{\text {th }}$ & Maturity threshold for spawning event [dimensionless] & $0-\infty$ & 0.1 \\
\hline age $_{\max }$ & Maximum age [years] & $0-\infty$ & 7 \\
\hline age $_{\text {max,larvae }}$ & Maximum age of larvae [years] & $0-a g e_{\max }$ & 2 \\
\hline$X_{\text {bloom }}$ & Food concentration during algae bloom & $0-\infty$ & 10 \\
\hline$X_{\text {open }}$ & Food concentration in open water & $0-X_{\text {bloom }}$ & 0.2 \\
\hline$X_{\text {ice }}$ & Food concentration underneath the ice & $0-X_{\text {bloom }}$ & 0.7 \\
\hline mortprorp & Vitality based mortality parameter [dimensionless] & $0-1$ & 0.5 \\
\hline$t_{\max }$ & Simulation time [years] & $0-\infty$ & 16 \\
\hline
\end{tabular}

grow only during their metabolically active period. Daily increment in body length $l$ is determined as such: $\frac{\Delta l}{\Delta t}=r_{\mathrm{B}}\left(f \times l_{\mathrm{M}}-l\right)$

$f$ is the scaled functional response $(\hat{f}=x /(x+K)$, with food availability (density) $x$ and the half saturation food density $K), r_{\mathrm{B}}$ is the von Bertalanffy growth rate, $l_{\mathrm{M}}$ the maximum length. If $\Delta l / \Delta t$ is negative, krill will shrink in size which is in accordance with observations (e.g. Kawaguchi et al., 2006). Parameters have been calibrated to reflect typical concave growth curves that result in individual krill sizes just below $6 \mathrm{~cm}$ (e.g. Candy and Kawaguchi, 2006) over krill's lifespan. The amount of shrinkage will be added to the state variable "shrinkage" as a measure of vitality or hunger stress, respectively. Furthermore we assume continuous growth instead of allowing growth only after moulting, which is a frequently used simplification (e.g. Murphy and Reid, 2001) and in line with the Dynamic Budget Theory (Kooijman, 2009) that assumes continuous growth of the so called "structural length".

It is important to mention that in our conceptual model krill does not exploit the food resource, i.e. food availability $x$ is not decreased by krill but only depends on the environmental conditions (see section environment). This is in line with the observation that only $3 \%$ of daily phytoplankton production is consumed by krill (Miller et al., 1985 as cited in Hill et al., 2006), but certainly will not be true locally for plankton patches exploited by large swarms of krill.

Reproduction: Only adult krill reproduce $(l>3 \mathrm{~cm})$. In the model each krill has a maturity state variable $m$ which potentially increases on a daily basis if it is metabolically active and adult, i.e.: $\frac{\Delta m}{\Delta t}=f \times r_{\mathrm{B}} \times \frac{l^{2}}{l_{\max }^{2}}$

If maturity state exceeds a threshold $m_{\text {th }}$ then a reproduction event happens and a new krill larva hatches and the maturity status $m$ of the mother is set to zero. Maturity status is only updated during time steps (days) when there was a positive growth increment, i.e. if krill is shrinking it does not invest in reproduction. We do not explicitly model the egg life stages to avoid exhaustive number of entities. If the metabolic state switches from active to reduced the maturity status is also set to zero to reflect the regression of sexual organs in krill during winter (Kawaguchi et al., 2007). For the reference parameter set the maturity threshold is set in a way that usually only one spawning event per season per individual happens, but in principle multiple spawning events can be simulated by lowering the maturity threshold. Although multiple spawning events have been reported (e.g. Tarling et al., 2007) we have decided to reduce the number of spawning event for computational reasons.

Mortality: Krill can die in three ways: (i) after 7 years every krill dies (5-7 years life cycle is reported in Siegel and Nicol, 2000), (ii) if krill stays more than two years in the larval state, (iii) or if cumulative shrinkage exceeds half of the current body length in krill.

Environment: In the peak of summer, the model arena (all 33 patches) is ice free. Over the following nine months ice cover increases linearly to its maximum extent (Fig. 1), i.e. expansion phase of sea ice takes longer than sea ice retreat ( 3 months, Knox, 2007). The maximum ice expansion is determined by the parameter icecover. Values of icecover range between $0 \%$ and $100 \%$ and specify the maximum ice cover that can occur along the South-North gradient. A single patch can only be fully covered by ice or completely ice free.

Whenever ice has been removed from a grid cell we assume that an algae bloom will occur which will last for a given time. This time is called vegetation period $v_{\mathrm{g}}$ and is set to 120 days (Knox, 2007). This algae bloom is modelled by setting food availability $x$ of a patch to 10 . After the end of the algae bloom, food availability is set to 0.2 unless the grid cell freezes again. Under the ice, a food availability of $x_{\text {ice }}=0.7$ is assumed to reflect resources provided by ice algae and other alternative food resources. However, the food availability under the ice accessible for krill larvae is not well known and therefore we varied this parameter $x_{\text {ice }}$ between 0.1 and 2 . The effect of different food availabilities on krill growth is illustrated in Fig. 3.

This range of values of $x_{\text {ice }}$ was motivated by data from the literature where a value for chlorophyll of $0.1 \mathrm{mg} \mathrm{Chl} \mathrm{m}^{-3}$ is suggested as the minimum value that growth can happen and $5 \mathrm{mg} \mathrm{Chl} \mathrm{m}^{-3}$ as 


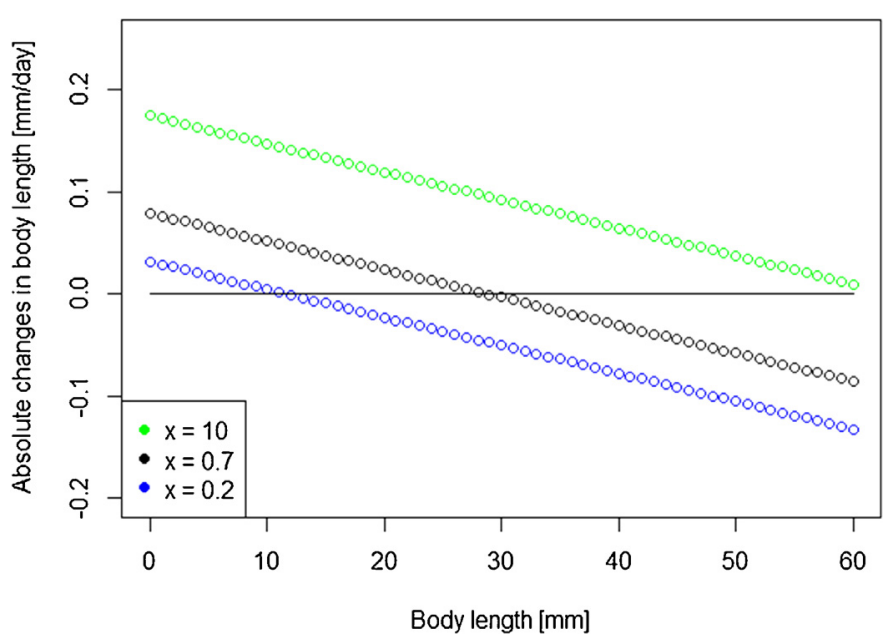

Fig. 3. Daily growth increments in mm depending on the body length for three levels of food availability $x$.

an optimal value (Priddle et al., 2003). Although food availability is not based on empirical data, our values correspond to measured Chlorophyll a concentrations (e.g. Tarling et al., 2006 reports a range of measured Chlorophyll concentrations between 0.07 and

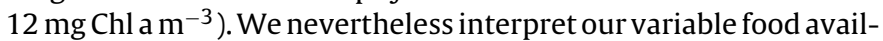
ability $x$ as a proxy without units. It is important to note that areas that are never covered by ice will have a constant food availability of $x=0.2$, since no algae bloom after ice melt occurs (Fig. 1).

Day length is updated each day and varies along the gradient. The maximum day length at the upper end (representing the northern range of krill) is $16.8 \mathrm{~h}$ and $24 \mathrm{~h}$ at the lower end (representing the southern end). Day length at a given grid cell y (ranging from 0 to 32 ) in the arena and the Julian day $t$ (ranging from 0 to 364) is given by: $d=24\left(-(0.3(1-(y) / 32)+0.2) \cos \left(\frac{t}{365} \times 360-180\right)+0.5\right)$

\subsection{Simulation experiments and scenarios}

We will present and discuss in the following the scenarios which result from all possible combinations of four trigger scenarios (ll, ff, lf, $f l ;$ for light and $f$ for food), two global change scenarios (icecover: $50 \%$ or $100 \%$ ), and different levels of food availability under the ice $\left(x_{\text {ice }}: 0.1-2\right)$. In addition we have performed benchmark simulations where krill does not switch its metabolic activity using the reference parameter set (Table 1 ). In the trigger scenarios the first letter represents the environmental factor (light or food) that switches krill metabolic activity on in summer and the second letter indicates the factor that switches the high metabolic activity state off. If the metabolic state is triggered by light, then the metabolic state switches as soon as a certain day length is reached. Critical day length is $12 \mathrm{~h}$ for the presented results, i.e. all krill individuals switch synchronously along the same latitudinal gradient. If the metabolic state is triggered by food, then metabolic activity switches whenever a certain food availability is met or exceeded ( $x=7.5$ for all presented results). This threshold will be only met during the algae bloom. In the model, krill can only switch their metabolic state twice in one year (i.e. one on and one off). To investigate the impact of parameter changes on the model outcomes we have performed a sensitivity analysis that can be found in Table A1 in appendix II.

\section{Results}

Our sensitivity analysis revealed that duration of the algae bloom followed by the von Bertalanffy growth rate are the most sensitive parameters. For the remaining parameters the model is robust in respect to moderate changes in the parameters $(10 \%$, Table A1 in Appendix II). We also tested the model for extreme parameter values and did not find inconsistencies (Table A1).

Growth trajectories of individual krill depended on the location along the south-north gradient (Fig. 4). Krill did not reach their maturity at the northern end, since this area is not covered by sea ice long enough. Therefore larvae have to cope with the low food availability in the open water which results in a substantial reduction in body length (black trajectory in Fig. 4). Krill growth was best in the middle of the gradient and lower at the southern end of the gradient. If food was the sole trigger, krill did not experience negative growth once it reached maturity $(l>3 \mathrm{~cm}$, Fig. $4 \mathrm{a})$. This was different when light was the trigger (Fig. 4b) where krill experienced some negative growth after the end of the algae bloom. If adult krill does not switch its metabolic activity at all it experiences negative growth to such an extent that it will die well before the maximum life time (Fig. $4 a$ and $b$, red trajectory).

At the population level, we compared mean annual local population growth rates for the four different trigger scenarios along the south-north gradient (Fig. 5). Each local population (grid cell) had been initialized with 10 individual larvae and the simulations ran for 15 years. Therefore, we calculated for each patch the annual population growth rate $\lambda$ as the 15 th square
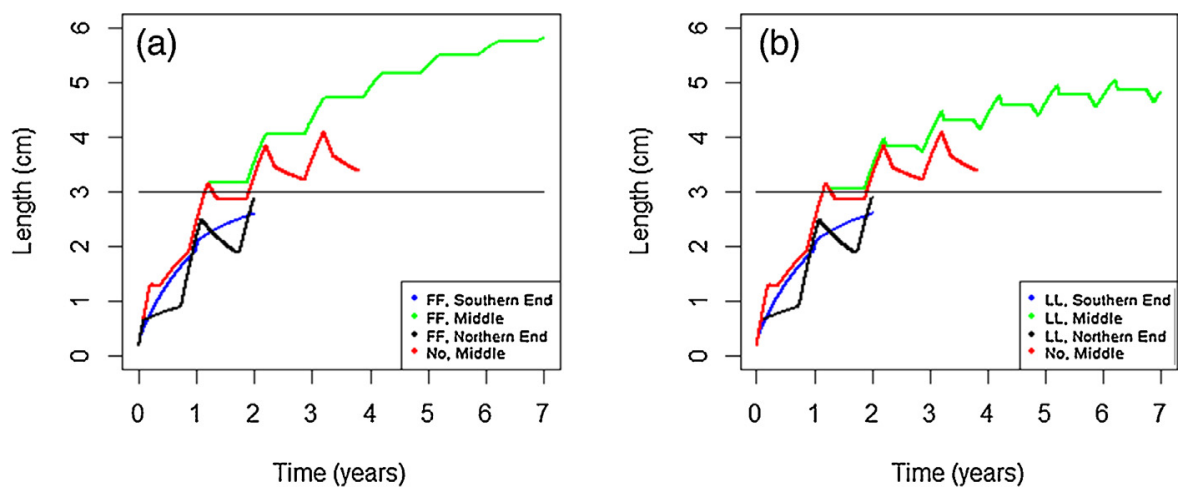

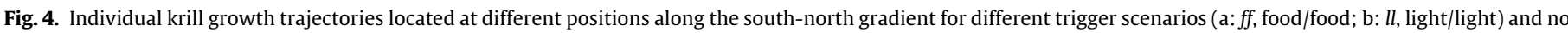

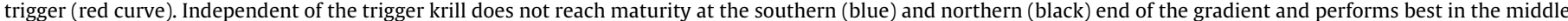

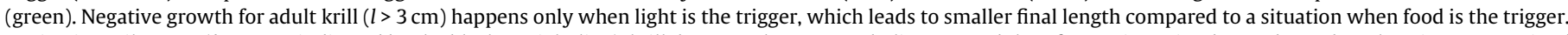

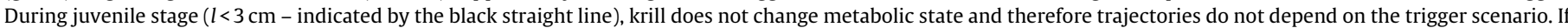

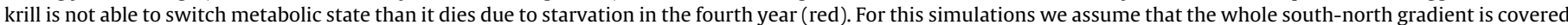

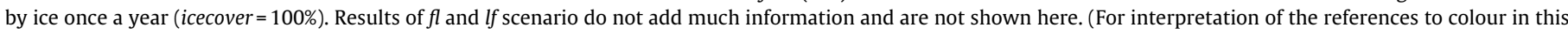
figure legend, the reader is referred to the web version of this article). 
root of the ratio of final population and initial population size $\left.\left(\lambda=\left(N_{\text {final }} / N_{\text {init }}\right) \hat{(1} 1 / t_{\text {simulation }}\right)\right)$ : In all four combinations of trigger scenarios, population growth rates were highest in the middle of the gradient, whereas growth was limited at the southern end due to the shorter duration of the algae bloom and at the northern end due to food limitation for larvae because of the short duration of the ice cover. Local annual population growth rates differed only slightly between the trigger scenarios, except for the light/light scenario that performed worst (Fig. 5). No switching of metabolic activity would be superior at the southern end (patch $=-10$ and patch $=-9$ ) of krill's range, where it is beneficial to stay active to not miss one of the few days of algae bloom and where no open water occurs because algae bloom is directly followed by sea ice cover (Fig. 5, orange trajectory).

To explore the impact of food content under the ice $x_{\text {ice }}$ on the local annual population growth rates, we considered two trigger scenarios ( $l l$ and $f f$ ) for this experiment (Fig. 6). Major differences between the trigger scenarios were found only at high food availability under the ice $x_{\text {ice }} \geq 1.5$ and at the southern end of the gradient. This suggests that if the food availability under the ice is sufficiently high, even adults can benefit from it and continue their growing phase if light is the trigger. Other differences between the trigger scenarios are more subtle and highlighted by the bottom graph visualizing the difference of local annual growth rates of the two 'trigger' scenarios.

For a global change scenario, only half of the gradient was covered by ice during the year (icecover $=50 \%$; Fig. 7); in this scenario, the potential habitat is approximately reduced by $50 \%$ compared to

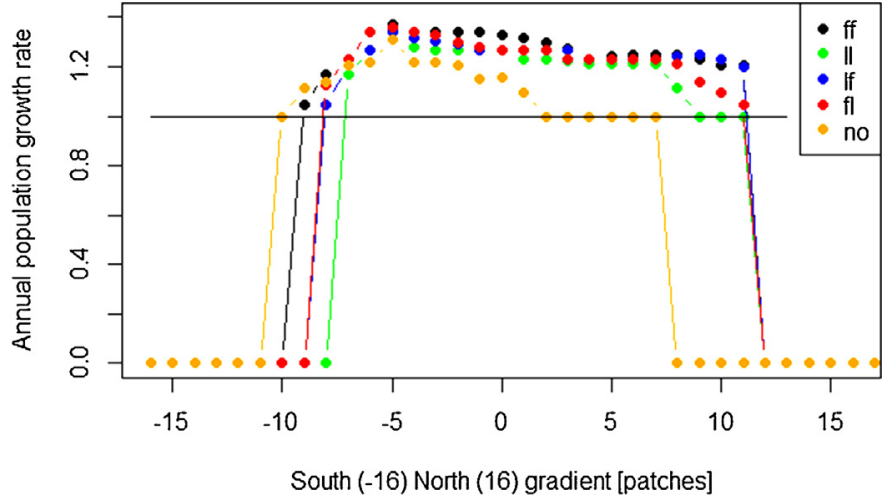

Fig. 5. Local annual population growth rates for four 'trigger' scenarios along the south-north gradient and one scenario where krill does not change its metabolic activity (no). Apart from the scenario where krill does not change metabolic activity the light/light scenario (ll) performs worst (green). If krill does not switch metabolic activity it can persist at the southern end of the krill distribution. Switching metabolic activity is not beneficial since algae bloom is directly succeeded by ice instead of a period of open water with low food availability. For this simulations we assume that the whole south-north gradient is covered by ice once a year (icecover $=100 \%$ ). (For interpretation of the references to colour in this figure legend, the reader is referred to the web version of this article).

the scenario with icecover $=100 \%$ (Fig. 6). Potential species distribution in terms of habitat quality and, in turn, local population growth rate, shifted to the south and the habitat loss in the ice free zone could not be fully compensated (Fig. 7). The interactions between

\section{(a) Local annual population growth rate, if}

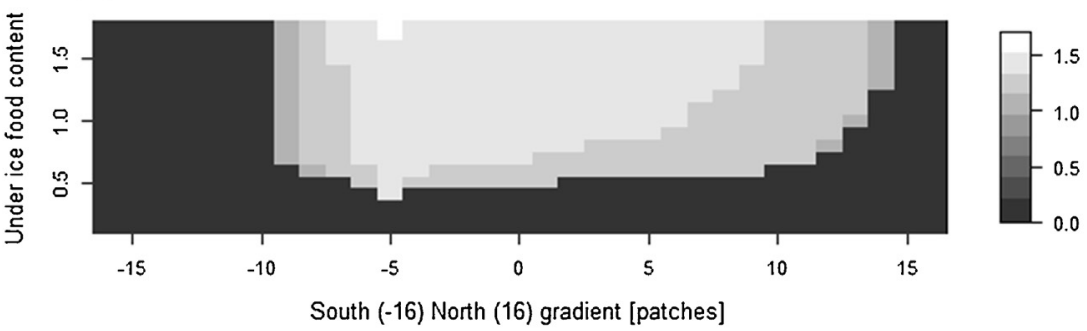

(b) Local annual population growth rate, II

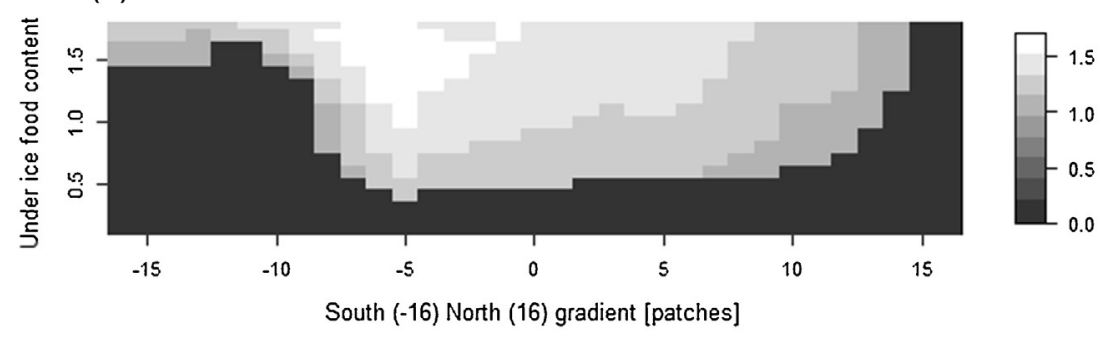

(c) Difference between growth rates in panel (a) and (b)

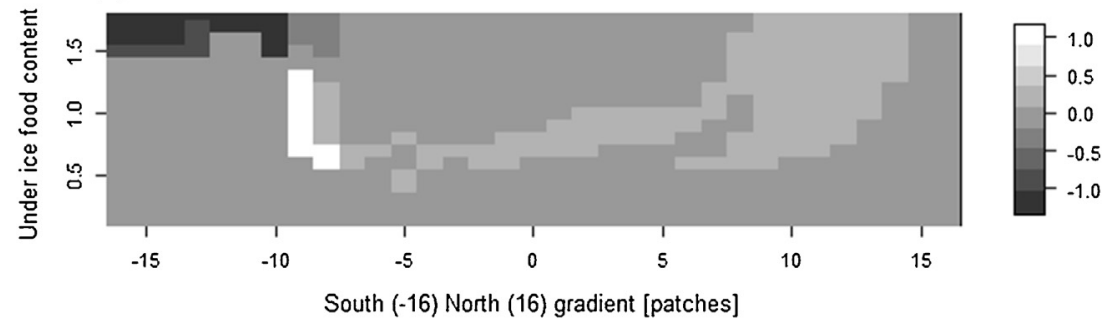

Fig. 6. Local population growth rates along the south-north gradient for different food availabilities under the ice (0.1-1.8). The trigger for metabolic switching is (a) food (ff) or (b) light (ll). The bottom panel (c) shows the difference between the growth rates in (a) and (b). For these simulation all grid cells have been covered by ice at some point of the year (icecover $=100 \%$ ). 
(a)

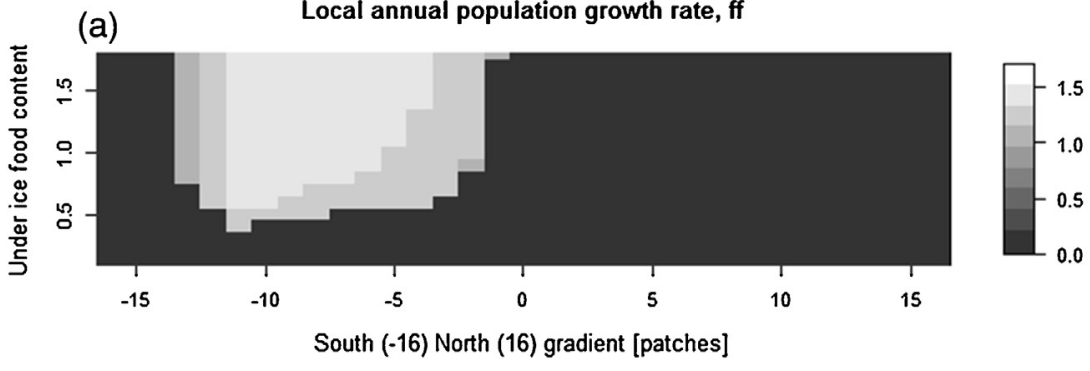

(b)

Local annual population growth rate, II

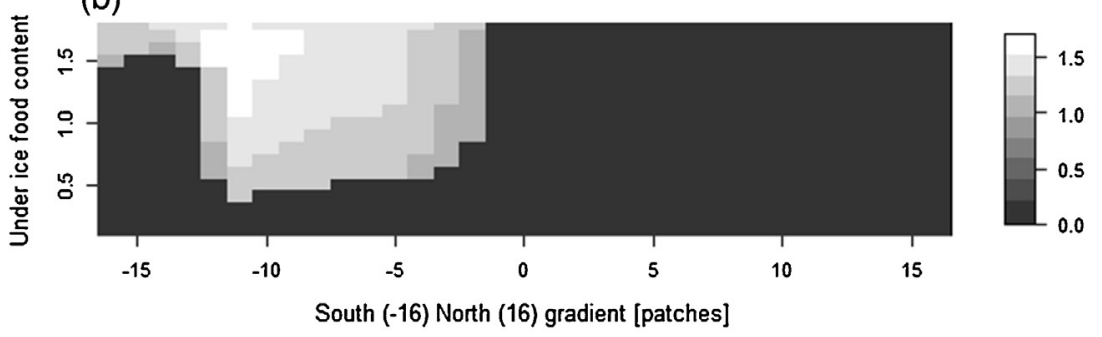

(c) Difference between growth rates in panel (a) and (b)

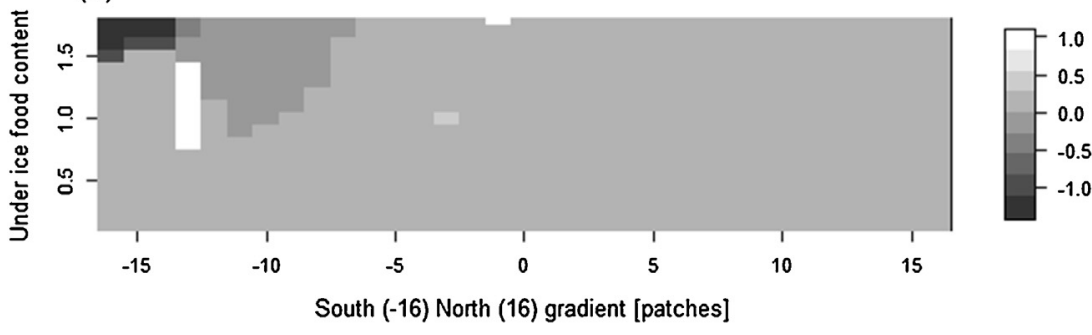

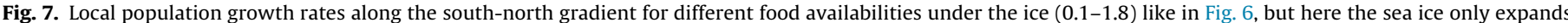
to the middle of the gradient (icecover $=50 \%$; cf. Fig. 1). Compared to Fig. 6 the species distribution shifts to the south and contracts.

food content under the ice, position along the gradient and the trigger' remained the same as in the original scenario (icecover $=100 \%$, Fig. 6).

Age-dependent body size, taken after 15 simulation years, were determined for the entire, global population for the two trigger scenarios light/light $(l l)$ and food/food ( $f f)$. Krill grew larger if the trigger was food (Fig. 8a). Global change effects could not be inferred from the body length distributions of the global populations (Fig. 8b), which is in contrast to effects on local populations (Figs. 6 and 7).

\section{Discussion}

Endogenous clocks in animals have been identified and well studied for some model species, but we are only beginning to understand how the clocks and their synchronization by environmental 'Zeitgeber' impact the ecology of species (Kronfeld-Schor et al., 2013). However, to assess a species' potential to cope with climate change it will be important to understand if and how phenology is based on endogenous clocks (Helm et al., 2013). Our current study demonstrates that in the context of different food availabilities under sea ice and spatio-temporal sea ice dynamics, different triggers and their combinations could have a profound impact on krill population structure, local population growth and its distribution. Nevertheless, these results are from a conceptual model where well known complicating factors are purposefully neglected to gain a basic understanding on which one can build upon. When interpreting our results it is important to bear in mind that spatio-temporal heterogeneities of sea ice cover and food availability as well as individual adaptation (e.g. migration) are not yet considered.

\subsection{Species distribution of krill}

Krill has a circumpolar and relatively broad latitudinal distribution (Atkinson et al., 2004). Species distribution models for krill identified abiotic factors such as distance from continental shelf break, water temperature, and water salinity to be important (Murase et al., 2013). Biotic factors have also been suggested to determine the habitat distribution of krill such as food availability (Hill et al., 2013) and competing species (Loeb et al., 1997). A series of studies deal with likely and already observed shifts in the species distribution of krill (Atkinson et al., 2004, Hill et al., 2013).

Our study reveals a possible combined effect of the food availability and the trigger of metabolic switching on the local population growth rate of krill (Figs. 6 and 7). Interestingly, for a range of scenarios for food availability under the ice from moderate to low the impact of the different triggers was less pronounced (Figs. 6 and 7). Under these conditions, the southern distribution of krill is rather limited by the short duration of the algae bloom after ice melt. Thus, the optimal strategy at its southerly distribution is that metabolic activity is triggered, i.e., switched on and off by a certain threshold food concentration (Fig. 5).

In contrast, the northern distribution of krill is limited by the short duration of sea ice cover that mainly affects larval development and does not allow individuals to reach maturity. The northern range of krill shifted substantially southwards if krill does not switch metabolic activity at all, because adult krill is not able to 

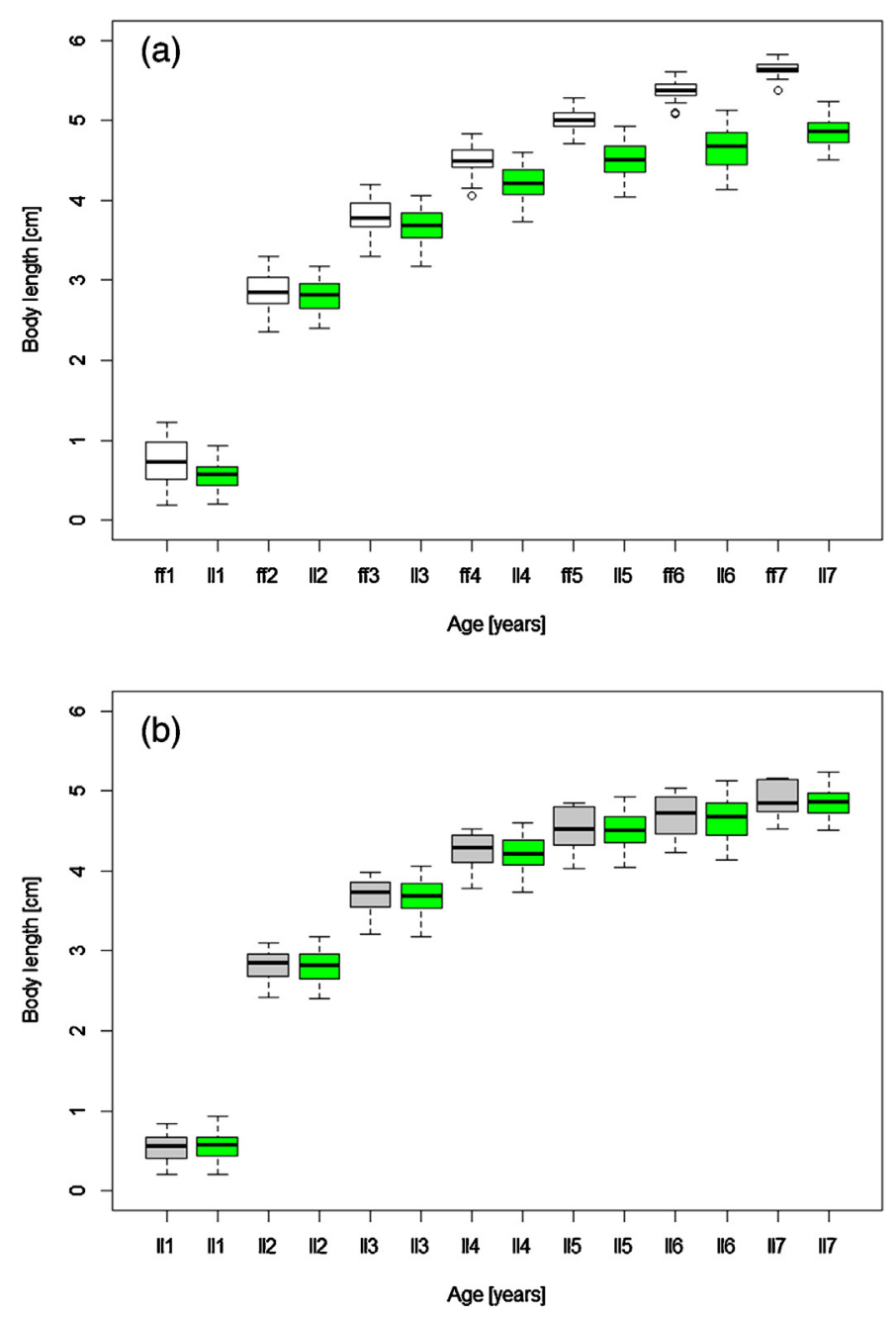

Fig. 8. Body length distributions depending on age for two different trigger scenarios (panel a; white: food as trigger, green: light as trigger for metabolic switching). In panel $b$ the effect of climate change is shown, i.e. for the grey boxes maximum ice cover was $50 \%$ whereas for the green boxes $100 \%$. Light has triggered metabolic switching for both experiments in panel b. (For interpretation of the references to colour in this figure legend, the reader is referred to the web version of this article).

persist for a long time in a low food environment (Fig. 5). Overall, the qualitative response to climate change in terms of decline in the sea ice cover is the same for all triggers scenarios (Fig. 7), i.e. krill occurrences will shift to the south, which is in accordance with field observations (Atkinson et al., 2004). However, the response may be more trigger-specific as more details are included into the model with regards to the spatio-temporal food availability and behaviour of krill.

\subsection{Length distribution}

Body size distributions of krill are well observed and relatively easily accessible from surveys (Candy and Kawaguchi, 2006). The simulated length-size frequency distributions differ depending on the trigger that switches metabolic activity (Fig. 8). For small body lengths differences between trigger scenarios are hardly detectable which makes sense since no metabolic switching is suggested for larvae and juveniles (Meyer 2012). In contrast, older krill grow differently depending on the trigger.

The trigger 'food' has a homogenizing effect on the size distributions, which reflects our model assumption that algae bloom occurs in the same way along the gradient, but at different times. If the trigger is day length (light), krill's metabolic activity and the algae bloom may not be perfectly synchronized along the south-north gradient which results in a slower growth or even in shrinking in accordance with field observations (Candy and Kawaguchi, 2006). Environmental changes, i.e. reduced sea ice cover caused by global warming, changes dramatically local population dynamics and species distribution (compare Figs. 6 and 7), the overall population size structures cannot be told apart between the global change and the standard scenario (Fig. $8 \mathrm{~b}$ ). This reflects the effect that the potential krill habitat is compressed and shifted.

However in the real system the new more southern habitat will certainly show new features that we have not yet considered such as lower temperatures, and less sun light (Quetin et al., 2007). Therefore, the reported length frequency distribution results cannot yet be confronted with empirical observations for two reasons: (i) the conceptual model does not yet include enough details (e.g. lack of movement) and (ii) specific survey data of particular locations do not contain all age classes (e.g. Murphy and Reid, 2001, Tarling et al., 2006).

\section{Conclusions}

Our simulation study clearly demonstrates how the details of the spatio-temporal sea ice dynamics, food availability under the ice, and the chronobiology can strongly affect both krill species distribution and local population dynamics and structure. Although a lot of pioneering work has been done on the chronobiology of krill (Teschke et al., 2007, 2008, 2011, Meyer et al., 2010), it is not yet clear which environmental factors are responsible for the seasonal dynamics of krill's metabolic activity. By comparing different trigger scenarios, our model provides insights that help identify the trigger inversely by comparing simulated and observed patterns. To project how krill will be affected by a changing environment in the Southern Ocean we have to understand its individual behavioural and physiological response to changing environmental conditions both with observations and models. Therefore we have investigated in this conceptual model the individual response of krill to specific environmental conditions at a fixed location along a south-north gradient. This first step will allow us to explore the role of krill behaviour such as migration in a temporally and spatially heterogeneous environment for more detailed projections including migration.

\section{Acknowledgements}

We thank all members of the Helmholtz Virtual Institute PolarTime and all other participants of our project meetings for the constructive discussions on the model. J.G. also wants to thank the participants of the 'Detecting, projecting and managing the impacts of change in Southern Ocean ecosystems' session at the IMBER open science meeting in Bergen 2014 for comments. We particularly would like to thank two reviewers for their extremely helpful and detailed comments. The study has been funded by the Helmholtz Virtual Institute "PolarTime" (VH-VI-500: Biological timing in a changing marine environment - clocks and rhythms in polar pelagic organisms). This work is a contribution to the research program PACES II (topic 1, workpackage 5 of the Alfred Wegener Institute).

\section{Appendix A. Supplementary data}

Supplementary data associated with this article can be found, in the online version, at http://dx.doi.org/10.1016/ j.ecolmodel.2015.02.009. 


\section{References}

Alonzo, S.H., Mangel, M., 2001. Survival strategies and growth of krill: avoiding predators in space and time. Mar. Ecol. Progress Ser. 209, 203-217.

Atkinson, A., Siegel, V., Pakhomov, E., Rothery, P., 2004. Long-term decline in krill stock and increase in salps within the Southern Ocean. Nature 432, 100-103.

Candy, S.G., Kawaguchi, S., 2006. Modelling growth of Antarctic krill. II. Novel approach to describing the growth trajectory. Mar. Ecol. Progress Ser. 306, $17-30$

Daly, K.L., 1990. Overwintering development, growth, and feeding of larval Euphausia superba in the Antarctic marginal ice-zone. Limnol. Oceanogr. 35, 1564-1576.

Everson, E., 2000. Biology Ecology and Fisheries. Blackwell Science, London.

Fach, B.A., Hofmann, E.E., Murphy, E.J., 2002. Modeling studies of antarctic krill Euphausia superba survival during transport across the Scotia Sea. Mar. Ecol. Progress Ser. 231, 187-203.

Grimm, V., Berger, U., Bastiansen, F., Eliassen, S., Ginot, V., Giske, J., Goss-Custard, J., Grand, T., Heinz, S.K., Huse, G., Huth, A., Jepsen, J.U., Jorgensen, C., Mooij, W.M., Muller, B., Pe'er, G., Piou, C., Railsback, S.F., Robbins, A.M., Robbins, M.M., Rossmanith, E., Ruger, N., Strand, E., Souissi, S., Stillman, R.A., Vabo, R., Visser, U., DeAngelis, D.L., 2006. A standard protocol for describing individual-based and agent-based models. Ecol. Model. 198, 115-126.

Grimm, V., Berger, U., DeAngelis, D.L., Polhill, J.G., Giske, J., Railsback, S.F., 2010. The ODD protocol: a review and first update. Ecol. Model. 221, 2760-2768.

Helm, B., Ben-Shlomo, R., Sheriff, M.J., Hut, R.A., Foster, R., Barnes, B.M., Dominoni, D., 2013. Annual rhythms that underlie phenology: biological time-keeping meets environmental change. Proc. R. Soc. B-Biol. Sci., 280.

Hill, S.L., Keeble, K., Atkinson, A., Murphy, E.J., 2012. A foodweb model to explore uncertainties in the South Georgia shelf pelagic ecosystem. Deep-Sea Res. Part II-Top.Stud. Oceanogr. 59, 237-252.

Hill, S.L., Murphy, E.J., Reid, K., Trathan, P.N., Constable, A.J., 2006. Modelling Southern Ocean ecosystems: krill, the food-web, and the impacts of harvesting. Biol.Rev. 81, 581-608.

Hill, S.L., Phillips, T., Atkinson, A., 2013. Potential Climate Change Effects on the Habitat of Antarctic Krill in the Weddell Quadrant of the Southern Ocean. Plos One, 8.

Jager, T., Martin, B.T., Zimmer, E.I., 2013. DEBkiss or the quest for the simplest generic model of animal life history. J. Theor. Biol. 328, 9-18.

Jia, Z.N., Virtue, P., Swadling, K.M., Kawaguchi, S., 2014. A photographic documentation of the development of Antarctic krill (Euphausia superba) from egg to early juvenile. Polar Biol. 37, 165-179.

Kawaguchi, S., Candy, S.G., King, R., Naganobu, M., Nicol, S., 2006. Modelling growth of Antarctic krill: I. Growth trends with sex, length, season, and region. Mar. Ecol. Progress Ser. 306, 1-15.

Kawaguchi, S., Ishida, A., King, R., Raymond, B., Waller, N., Constable, A., Nicol, S., Wakita, M., Ishimatsu, A., 2013. Risk maps for Antarctic krill under projected Southern Ocean acidification. Nat. Clim. Change 3, 843-847.

Kawaguchi, S., Yoshida, T., Finley, L., Cramp, P., Nicol, S., 2007. The krill maturity cycle: a conceptual model of the seasonal cycle in Antarctic krill. Polar Biol. 30, 689-698.

Knox, G.A., 2007. Biology of the Southern Ocean. Taylor and Francis Group, Boca Raton.

Kooijman, B., 2009. Dynamic Energy Budget Theory for Metabolic Organisation. Cambridge University Press, Cambridge.

Kronfeld-Schor, N., Bloch, G., Schwartz, W.J., 2013. Animal clocks: when science meets nature. In: Proc. R. Soc. B-Biol. Sci, p. 280.

Loeb, V., Siegel, V., HolmHansen, O., Hewitt, R., Fraser, W., Trivelpiece, W., Trivelpiece, S., 1997. Effects of sea-ice extent and krill or salp dominance on the Antarctic food web. Nature 387, 897-900.

Lowe, A.T., Ross, R.M., Quetin, L.B., Vernet, M., Fritsen, C.H., 2012. Simulating larval Antarctic krill growth and condition factor during fall and winter in response to environmental variability. Mar. Ecol. Progress Ser. 452, 27-43.

Meyer, B., 2012. The overwintering of Antarctic krill. Euphausia superba, from an ecophysiological perspective. Polar Biol. 35, 15-37.

Meyer, B., Auerswald, L., Siegel, V., Spahic, S., Pape, C., Fach, B.A., Teschke, M., Lopata, A.L., Fuentes, V., 2010. Seasonal variation in body composition, metabolic activity, feeding, and growth of adult krill Euphausia superba in the Lazarev Sea. Mar. Ecol. Progress Ser. 398, 1-18.

Meyer, B., Fuentes, V., Guerra, C., Schmidt, K., Atkinson, A., Spahic, S., Cisewski, B. Freier, U., Olariaga, A., Bathmann, U., 2009. Physiology, growth, and development of larval krill Euphausia superba in autumn and winter in the Lazarev Sea, Antarctica. Limnol. Oceanogr. 54, 1595-1614.

Miller, D.G.M.H.I., Henry, J., Abrams, R.W., Cooper, J., 1985. The relationship between krill food requirements and phytoplankton production in a sector of the Southern Indian Ocean. In: Siegfried, W.R., Condy, P.R.L.R.M. (Eds.), Antarctic Nutrient Cycles and Food Webs. Springer-Verlag, Berlin, pp. 363-371.

Montes-Hugo, M., Doney, S.C., Ducklow, H.W., Fraser, W., Martinson, D., Stammerjohn, S.E., Schofield, O., 2009. Recent changes in phytoplankton communities associated with rapid regional climate change along the Western Antarctic Peninsula. Science 323, 1470-1473.

Murase, H., Kitakado, T., Hakamada, T., Matsuoka, K., Nishiwaki, S., Naganobu, M. 2013. Spatial distribution of Antarctic minke whales (Balaenoptera bonaerensis) in relation to spatial distributions of krill in the Ross Sea Antarctica. Fish. Oceanogr. 22, 154-173.

Murphy, E.J., Reid, K., 2001. Modelling Southern Ocean krill population dynamics: biological processes generating fluctuations in the South Georgia ecosystem. Mar. Ecol. Progress Ser. 217, 175-189.

Nielsen, J.L., Ruggerone, G.T., Zimmerman, C.E., 2013. Adaptive strategies and life history characteristics in a warming climate: Salmon in the Arctic? Environ.Biol. Fishes 96, 1187-1226

Priddle, J., Whitehouse, M.J., Ward, P., Shreeve, R.S., Brierley, A.S., Atkinson, A. Watkins, J.L., Brandon, M.A., Cripps, G.C., 2003. Biogeochemistry of a Southern Ocean plankton ecosystem: using natural variability in community composition to study the role of metazooplankton in carbon and nitrogen cycles. J. Geophys. Res.-Oceans, 108

Quetin, L.B., Ross, R.M., Fritsen, C.H., Vernet, M., 2007. Ecological responses of Antarctic krill to environmental variability: can we predict the future? Antarct. Sci. 19 253-266.

Schofield, O., Ducklow, H.W., Martinson, D.G., Meredith, M.P., Moline, M.A., Fraser, W.R., 2010. How do polar marine ecosystems respond to rapid climate change? Science 328, 1520-1523.

Siegel, V., Nicol, S., 2000. Population parameters. In: Everson, I. (Ed.), Krill: Biology Ecology and Fisheries. Blackwell, London, pp. 103-149.

Skvarca, P., Rack, W., Rott, H., Donangelo, T.I.Y., 1999. Climatic trend and the retreat and disintegration of ice shelves on the Antarctic Peninsula: an overview. Polar Res. 18, 151-157.

Tarling, G.A., Shreeve, R.S., Hirst, A.G., Atkinson, A., Pond, D.W., Murphy, E.J., Watkins, J.L., 2006. Natural growth rates in Antarctic krill (Euphausia superba): I Improving methodology and predicting intermolt period. Limnol. Oceanogr. 51, 959-972.

Tarling, G.A., Cuzin-Roudy, J., Thorpe, S.E., Shreeve, R.S., Ward, P., Murphy, E.J., 2007. Recruitment of Antarctic krill Euphausia superba in the South Georgia region: adult fecundity and the fate of larvae. Mar. Ecol. Progress Ser. 331, 161-179.

Teschke, M., Kawaguchi, S., Meyer, B., 2007. Simulated light regimes affect feeding and metabolism of Antarctic krill Euphausia superba. Limnol. Oceanogr. 52, 1046-1054.

Teschke, M., Kawaguchi, S., Meyer, B., 2008. Effects of simulated light regimes on maturity and body composition of Antarctic krill Euphausia superba. Mar. Biol $154,315-324$.

Teschke, M., Wendt, S., Kawaguchi, S., Kramer, A., Meyer, B., 2011. A Circadian clock in Antarctic Krill: an endogenous timing system governs metabolic output rhythms in the euphausid species Euphausia superba. Plos One, 6.

Vaughan, D.G., Marshall, G.J., Connolley, W.M., Parkinson, C., Mulvaney, R., Hodgson, D.A., King, J.C., Pudsey, C.J., Turner, J., 2003. Recent rapid regional climate warming on the Antarctic Peninsula. Clim. Change 60, 243-274.

Walther, G.R., Post, E., Convey, P., Menzel, A., Parmesan, C., Beebee, T.J.C., Fromentin, J.M., Hoegh-Guldberg, O., Bairlein, F., 2002. Ecological responses to recent climate change. Nature 416, 389-395.

Wilensky, U., 1999. NetLogo. 〈http://ccl.northwestern.edu/netlogo/〉. Center for Connected Learning and Computer-Based Modeling, Northwestern University. Evanston, IL. 